\title{
Iron Deficiency Anemia as a Risk Factor for First Febrile Seizures a Case Control Study
}

\author{
V. Ramgopal Rao ${ }^{\circledR 1}$, P. Anil Kumar ${ }^{\circledR 2}$ \\ ${ }^{1}$ Assistant Professor, Department of Pediatrics, Medi Citi Institute of Medical Sciences, Ghanpur, Telangana, India, ${ }^{2}$ Assistant Professor, Department of Pediatrics, \\ Kakatiya Medical College, Warangal, Telangana, India.
}

\section{Abstract}

Background: Febrile seizures in children are a common problem. Iron deficiency anaemia is known, among other contributing factors, to be an aggravating factor in febrile seizures. Iron deficiency anaemia is a condition that can be avoided and managed. The study goal was to identify iron deficiency anaemia as a trigger factor for febrile seizures (FS). To determine the association between Iron Deficiency Anemia (IDA) and the first episode of febrile seizures (FFS). Subjects and Methods: Investigation like hemoglobin, blood indices (MCV, MCH), and serum iron and serum ferritin are done for detection of iron deficiency anaemia and their relationship with the first episode of febrile seizure was observed. Results: In our study comprising 50 cases and 50 controls, 58\% (29) of cases were diagnosed as IDA with FS, 18\% (9) of controls were diagnosed as IDA with Febrile Illness (FI). This suggests IDA as a risk factor for febrile seizures with a significant $\mathrm{P}$ value of $<0.001$. Among 50 cases $42 \%$ (21) cases have FS without IDA and among 50 controls $82 \%$ (41) controls have FI without IDA were present in the current study. Conclusion: IDA was more common in children with FS than in those with febrile illness (FI) disease alone. The result suggests that the IDA can be a contributing factor to the FFS. Screening of IDA of children with FFS should be regarded. Fever can worsen the negative effects of anaemia or iron deficiency on the brain, which can lead to seizures.

Keywords: Seizures, Iron Deficiency Anaemia (IDA), Serum Iron, Serum Ferritin

Corresponding Author: P. Anil Kumar, Assistant Professor, Department of Pediatrics, Kakatiya Medical College, Warangal, Telangana, India. E-mail: drpanialkumar@gmail.com

Received: 25 May $2020 \quad$ Revised: 30 July 2020

\section{Introduction}

Febrile Seizures (FS) is the most common convulsive disorder of children and occurs in $2-5 \%$ of the overall number of children (or 4.8/1000) were impacted per year. ${ }^{[1]}$ Febrile Seizure was classified as fever-related seizures. The disorder presents with a fever of $38^{\circ} \mathrm{C}$ in children from 6 months to 6 years old and does not include signs of central nervous system disorders or any other potential triggers. ${ }^{[1]}$ Trigger factors for this condition include a family history of convulsion or FS, brain injury, mothers who consume or drink alcoholic drinks and high fever. ${ }^{[2-6]}$ Since FS has the ability to progress to convulsion and epilepsy, several trials have been carried out to determine remedial risk factors for FS to decrease the occurrence and, subsequently, epilepsy and convulsion. ${ }^{[2,3,7-9]}$ The WHO 1995-2011 global anaemia report states that nearly $43 \%$ of babies, $38 \%$ of pregnant women, and $29 \%$ of nonpregnant women and $29 \%$ of all reproductive-age people worldwide suffered from anaemia, equal to 273 million young teenagers, 496 million non-pregnant, and 32 million pregnant
Accepted: 09 August 2020

Published: 28 December 2020

women. Percents of children from 6 to 59 months of age in Anemia community are 53.8 (39.9 to 63.9) in South East Asia region. ${ }^{[10]}$ Anemia (IDA) is one of the world's most severe issues in the diet. 46-66 percent of those below five are anaemic within developing nations. 58.5 percent of under-5 are anemic in India, according to NFHS-4. ${ }^{[1]}$

Iron is essential for neurological functions and brain growth. ${ }^{[12]}$ Given the age prevalence of IDA and FS, which play the same role as iron in neurotransmitter synthesis (such as GABA dopamine and serotonin), ${ }^{[13]}$ and certain enzymes, such as monoaminoxidase, the role of hemoglobin in carrying oxygen to the brain, and fever, that worsen symptoms induced by anemia, a relationship between IDA and FS is probable. Iron deficiency is postulated as a factor leading to febrile seizures in children and is easily reversed.

\section{Subjects and Methods}

\section{Source of Data}


This research would be a Prospective case-control study for both children with the first episode of febrile seizures and febrile illness in the Department of Paediatrics, Gandhi Medical College, Secunderabad from January 2017 to June 2018.

\section{Sample Size}

The survey size was determined using SPS based on an alpha error $(5 \%)$, beta error $(10 \%)$, test strength $=90 \%$, with $n 1$ cases $=36$, and $\mathrm{n} 2$ control cases $=36$. However, I am taking a sample size of 100 , cases $=50$ and controls $=50$ for better validation of results.

\section{Methods of Collection of Data}

(Including sampling procedure, if any) this is a prospective case-control study with a study period of 18 months from January 2017 to June 2018. This study includes two groups.

\section{Cases}

Includes 50 consecutive children admitted in pediatrics ward fulfilling the following:

\section{Inclusion Criteria}

- Children with first simple febrile seizure between 6 months and 5 years

\section{Exclusion Criteria}

- Children aged $<6$ months and $>5$ years.

- Children presenting with atypical febrile seizures.

- Children presenting with afebrile seizures or those having any signs of CNS infection or metabolic seizures.

- Those children with a history of birth asphyxia/developmental delay/epilepsy.

- Those children on Iron supplementation therapy.

- Very sick children.

- Children who fall into the Grade IV PEM category on IAP charts

- Family h/o Epilepsy/mental retardation

\section{Control Group}

Features 50 infants from 6 months to 5 years who have the febrile illness without convulsions. After obtaining informed consent from the parents of children to be enrolled for the study relevant history, examination and laboratory investigations were collected in a predesigned proforma.

\section{History}

Demographic data, seizure details, nature of the febrile illness, family history of epilepsy/ febrile seizures

\section{Examination}

The vitals of the child (HR, RR, peripheral pulses, blood pressure, and temperature) were recorded. General physical examination and nutritional status according to IAP weight for age classification were used to grade protein-energy malnutrition. Systemic examination was done as per the proforma.

\section{Investigations}

The following investigations were done in all cases and controls at the time of admission.

\section{Hemoglobin, blood indices (MCV, MCH, MCHC).}

2. Blood glucose: Random blood sugar was with glue stick and then confirmed by glucose oxidase peroxidase method.

3. Serum electrolytes (S. Sodium, S. Potassium and S. Chloride)

\section{S. Calcium}

5. Iron studies (S. Iron, S. Ferritin, TIBC).

All the patients were treated according to the diagnosis.

- An investigation like hemoglobin, blood indices (MCV, $\mathrm{MCH})$, serum iron and serum ferritin done for detection of iron deficiency anemia and their relationship with febrile seizure was observed.

Methods and diagnostic criteria for iron deficiency anaemia used in my study are as follows: ${ }^{[12]}$

- Hemoglobin $<11 \mathrm{~g} / \mathrm{dl}$,

- $\mathrm{MCV}<70 \mathrm{fl}$,

- $\mathrm{MCH}<27$ pg, and

- Serum ferritin $<12 \mu \mathrm{gm} / \mathrm{dl}$.

Statistical Analysis Data analyses were done using SPSS 20.0.

\section{Results}

Among 50 cases $36 \%$ (18) cases were $<1$ year, $30 \%$ (15) cases were $1-2$ years, $22 \%$ (11) cases were $2-3$ years, $6 \%$ (3) cases were $3-4$ years and $3 \%$ (3) cases were $>4$ years. Among 50 controls $54 \%$ (27) controls were $<1$ year, $16 \%$ (8) controls were $1-2$ years, $18 \%$ (9) controls were $2-3$ years, $10 \%(5)$ controls were $3-4$ years and $2 \%$ (1) controls were $>4$ years. In our study among 50 cases and 50 controls $62 \%$ (31) of the cases and controls were males while $38 \%$ (19) were females. The mean age of cases was $2.05 \pm 1.25$ years and the mean age among the control group was $1.71 \pm 1.20$ years.

Among 50 cases and 50 controls 35 cases $(70 \%)$ and 44 controls $(88 \%)$ had weight $<10 \mathrm{kgs}, 15$ cases $(30 \%)$ and 6 controls $(12 \%)$ had weight $>10 \mathrm{kgs}$. In the community monitoring, the average weight was $9.87 \pm 2.34 \mathrm{kgs}$ and $8.24 \pm 2.19 \mathrm{kgs}$. In the present study out of 50 cases, $100 \%$ (50) were of lower SES. Among 50 controls 96\% (48) of controls were of lower SES and 4\% (2) of controls were of middle SES. In the present study out of 50 cases of the first 


\begin{tabular}{lllll}
\hline \multicolumn{7}{l}{ Table 1: Demographic Data for Age and Gender Distribution for both Case and Controls } \\
\hline Age in years & Cases & $\%$ & Controls & \\
& F & $\%$ & F & $\%$ \\
\hline 1 year & 18 & 36.0 & 27 & 54.0 \\
\hline 1-2 year & 15 & 30.0 & 8 & 16.0 \\
\hline 2-3 years & 11 & 22.0 & 9 & 18.0 \\
\hline 3-4 years & 3 & 6.0 & 5 & 10.0 \\
\hline -5 years & 3 & 6.0 & 1 & 2.0 \\
\hline Total & 50 & 100.0 & 50 & 100.0 \\
\hline Mean \pm SD & $2.05 \pm 1.25$ & & $1.71 \pm 1.20$ & \\
\hline Gender & & & & 62.0 \\
\hline Male & 31 & 62.0 & 31 & 38.0 \\
\hline Female & 19 & 38.0 & 19 & 100 \\
\hline Total & 50 & 100 & 50 & \\
\hline
\end{tabular}

Table 2: Weight, Socio-Economic Status, Average Duration of Seizures, Comparison of Other Parameters, Family History of Febrile Seizures in Study Group

\begin{tabular}{lll}
\hline Weight $(\mathbf{k g})$ & Cases $(\mathbf{n}=\mathbf{5 0})$ & Controls $(\mathbf{n}=\mathbf{5 0})$ \\
$<10 \mathrm{~kg}$ & $35(70.0 \%)$ & $44(88.0 \%)$ \\
$>10 \mathrm{~kg}$ & $15(30.0 \%)$ & $6(12.0 \%)$ \\
\hline Mean $\pm \mathrm{SD}$ & $9.87 \pm 2.34$ & $8.24 \pm 2.19$ \\
\hline Socio-economic status & & \\
\hline Lower & $50(100.0 \%)$ & $48(96.0 \%)$ \\
\hline Middle & 0 & $2(4.0 \%)$ \\
\hline Upper & 0 & 0 \\
The average duration of seizures & & \\
$<5$ min & $39(78.0 \%)$ & 0 \\
$5-10$ min & $11(22.0 \%)$ & 0 \\
$>10$ mins & 0 & 0 \\
Other parameters & & \\
\hline Uprolling of eyes & $49(98.0 \%)$ & $0(0 \%)$ \\
Deviation of the angle of mouth & $16(32.0 \%)$ & $0(0 \%)$ \\
\hline Family history & & $1(2 \%)$ \\
Yes & $4(8.0 \%)$ & $49(98 \%)$ \\
\hline No & $46(92.0 \%)$ & \\
\hline
\end{tabular}

episode of simple febrile seizures $78 \%$ (39) cases of seizures lasted for $<5$ mins and $22 \%$ (11) cases of seizures lasted for 5-10 mins. In our study among 50 cases of the first episode of simple febrile seizures 49 (98\%) cases had up rolling of eyes and $16(32 \%)$ of cases had a deviation of angle of mouth. In the present study among 50 cases and 50 controls $8 \%(4)$ cases had a positive family history and $2 \%$ (1) controls had a positive family history. In the present study group of 50 cases and 50 controls, $41(82 \%)$ cases and $42(84 \%)$ controls have upper respiratory tract infections, $9(18 \%)$ cases and $8(16 \%)$ controls have acute gastroenteritis.

In the current analysis, the average $\mathrm{Hb}$ value in cases was 8.92 \pm 1.18 and control values were $9,55 \pm 0,96$, a mean $\mathrm{MCV}$ value of $67.03 \pm 15.64$, control value of $84.12 \pm 13.78$, and a mean MCH value of $30.60 \pm 13.81$ in cases and control values of $37.32 \pm 9.57$. The mean Serum Ferritin level was $45 \pm 64.09$ in our sample of 50 cases and 50 controls, whereas the mean Serum Ferritin level was $54.22 \pm 24.02$ in controls. 


\begin{tabular}{llll}
\hline \multicolumn{2}{l}{ Table 3: Mean Values of Various Blood Parameters } & & \\
\hline Parameters & Cases & Controls & P-value \\
\hline Hemoglobin & $8.92 \pm 1.18$ & $9.55 \pm 0.96$ & $<0.001^{* *}$ \\
MCV & $67.03 \pm 15.63$ & $84.12 \pm 13.78$ & $<0.001^{* *}$ \\
MCH & $30.60 \pm 13.81$ & $37.32 \pm 9.57$ & $0.006^{* *}$ \\
Serum ferritin & $45 \pm 64.09$ & $54.22 \pm 24.02$ & $\mathrm{P}=<0.03^{*}$ \\
Serum Iron & $77.65 \pm 44.71$ & $95.20 \pm 38.08$ & $\mathrm{P}=0.037^{*}$ \\
T1BC & $434.86 \pm 125.18$ & $354.14 \pm 103.10$ & $\mathrm{P}=0.001^{* *}$ \\
Serum Transferrin & $248.64 \pm 64.43$ & $290.42 \pm 49.62$ & $\mathrm{P}=<0.001^{* *}$ \\
\hline
\end{tabular}

The average serum iron level in our sample was $77.65 \pm 44.71$, and the average serum iron level in our controls was 95, $20+$ 38.08. The mean level of TIBC for this analysis in cases was $434.86 \pm 125.18$ and the mean level of TIBC in controls was $354.14 \pm 103.10$. Throughout this analysis, the average level of Serum Transferrin in this sample was $248.64 \pm 64.43$, and the mean amount in the controls was $290.42 \pm 4962$.

In our study comprising 50 cases and 50 controls, 58\% (29) of cases were diagnosed as IDA with FS, 18\% (9) of controls were diagnosed as IDA with FI. This suggests IDA as a risk factor for febrile seizures with a significant $P$ value of $<0.001$. Among 50 cases $42 \%$ (21) cases have FS without IDA and among 50 controls $82 \%$ (41) controls have FI without IDA were present in the current study. In the present study among 29 cases of IDA with FS 21 were males and 8 were females, among 21 cases of FS 10 were males and 11 were females.

\section{Discussion}

Febrile Seizures, particularly the simplistic ones, are very mild and have a temporal trend. However, the presence of a seizure can be a life-threatening incident, until it is handled emergently. This also has a huge mental effect on caregivers. Likewise, there is a substantial economic cost in the context of patient treatment and medical services. Complex FS can have severe morbidity as a consequence of executive dysfunction, hippocampal sclerosis and epilepsy. On a larger scale, the results of this study could enable us to follow a cost-efficient strategic plan and to establish a more successful protocol to avoid FS or repeated attacks in vulnerable children. Throughout the analysis, the average onset age for FS is 24 months, with an early onset between 6 months to 1 year in $36 \%$ of the cases. In the US population, regardless of no statistical importance, there is a surplus of male children. About $100 \%$ of patients reported severe tonic-clonic seizures. All cases were reported within 24 hours from seizure onset and single seizure in a febrile episode. FS family data was collected in 8 percent of cases and was marginally higher in others. The ancestral history of FS did not achieve statistical importance. In the analysis, with the exception of the initial change in body temperature at about 100-101 0 F range, there was little difference in peak temperature at entry between FS and FI classes. For all groups, the number of cases and controls inducing diseases was similar and the URTI was predominant. Children with FS also had further iron deficits relative to the FS control group in terms of low $\mathrm{HB}$, low $\mathrm{MCH}$, low MCV, low PF, minimal serum calcium, higher TIBC and low serum transferrin.

The period of seizures after initiation of fever: The earlier the length of reported fever, the greater the risk of recurrence. Among those with FS within one hour of initiation, the probability of recurrence at 1 year was 46 percent, contrasted with 39 percent for those with the previous fever of 1 to 24 hours and 15 percent for those with more than 24 hours of known FS fever. The reality that children in whom FS happens at the advent of fever has the greatest likelihood of recurrence and has consequences for prophylactic approaches that focus on the delivery of medications at the initiation of febrile illness. Millichap et al postulated a convulsive level above which the attack would precipitate. Berg et al noticed that 44 percent of babies experienced had less than 1 hour of fever at the time of their FS, while just 13 percent had more than 24 hours of fever. Throughout the present analysis, all cases reported within 24 hours of the initiation of fever were almost identical to the above-mentioned reports.

Febrile Status : The occurrence of febrile status and significant association with other complex features, neuron deficiency and focal seizures were not present in this study. Similar findings have been reported by Shinnar et al, with 14 percent of children having seizures lasting longer than 10 minutes, 9 percent longer than 15 minutes, and 5 percent longer than 30 minutes or febrile epileptic status. For this analysis, a cut-off term of $\geq 15$ minutes was used for the febrile condition, which is an older concept. We think the cut-off time of 15 minutes is realistic, because basic FS is, by nature, up to 10 to 15 minutes long. Data from animal experiments often show that long-term symptoms only exist while seizures last 20 minutes or longer by Dube et al. ${ }^{[14]}$ However, this was not the aim of this research. 
Table 4: Diagnosis

\begin{tabular}{llll}
\hline Diagnosis & Cases $(\mathbf{n}=\mathbf{5 0})$ & Controls $(\mathbf{n}=\mathbf{5 0})$ & P-value \\
\hline IDA & $29(58.0 \%)$ & $9(18 \%)$ & $0.00003^{* *}\left(<0.001^{* *}\right)$ \\
\hline FS & $21(42.0 \%)$ & 0 & \\
\hline Others & 0 & $41(82.0 \%)$ & \\
\hline
\end{tabular}

Type of seizures : Much of the FS are basic seizures. In the present study, basic febrile seizures accounted for 100 percent of seizures, which was close to the research by Livingston et al, with a plurality (96.9 percent) of basic FS seizures. Berg et al in 1996 found that 35 percent of children had at least 1 complex feature, including 16 percent focal length, 14 percent multiple seizures, and 13 percent prolonged duration. About 6 percent of children have at least 2 complex features, and 1 percent had all 3 complex features not included in the current report.

Appropriate intranasal, perinatal treatment, availability of appropriate meals for mothers is now enshrined in numerous policy services. Infant deaths and morbidity related to insufficient treatment were often alarming. There is also ample evidence for better maternal treatment to reduce neurodevelopmental morbidity in infants. The present research did not involve children who had been postponed for growth. Nonetheless, a strong association with perinatal variables may contribute to a stronger primary prevention approach for children with FS. Considering the role of Iron as a risk factor in FS, supplementation can be considered as a preventive approach to FS, which is a cost-effective strategy, particularly in developing countries such as India. Adequate evidence collected can often be used in clinical services such as IMNCI, responding to the interests of children in this age group, improving their capacity to enhance infant protection strategies with these goals in mind, prospectively planned multi-center trials requiring greater sampling sizes and advanced procedures are required to validate or reject findings.

\section{Conclusion}

The association between iron deficiency anaemia and febrile seizures was previously investigated without any definitive results and more data was presented for this study. All the less, the preference bias as well as the confusing social status appear unusual in this analysis. IDA was more frequent in children with Febrile Seizures than children with febrile illness alone. The findings indicate that IDA may be a risk factor for FFS. IDA monitoring should be done in children with FFS. Fever can worsen the negative effects of anaemia or iron deficiency on the brain, which can lead to seizures. Conversely, anaemia can be correlated with the frequency of a febrile disorder, and more serious patients may be more prone to cause epilepsy. Both studies performed to determine iron-deficiency anaemia were slightly lower in events relative to controls. It means that children with iron deficiency are more prone to have febrile seizures. A follow-up review of individuals confirmed to have iron deficiency at the time of the first febrile seizure to determine the occurrence of subsequent febrile seizures after iron-deficiency drugs would be of great significance.

\section{References}

1. Mikati MA, Robert AJH, Kleigman M, Behrman RE. Nelson Text Book of Pediatrics. Saunders Elsevier. 2016;593:28232856.

2. Nelson KB, Ellenberg JH. Prenatal and perinatal antecedents of febrile seizures. Ann Neurol. 1990;27(2):127-131. Available from: https://dx.doi.org/10.1002/ana.410270206.

3. Greenwood R, Golding J, Ross E, Verity C. Prenatal and perinatal antecedents of febrile convulsions and afebrile seizures: data from a national cohort study. Paediatr Perinat Epidemiol. 1998;12(S1):76-95. Available from: https://dx.doi. org/10.1046/j.1365-3016.1998.0120s1076.x.

4. American Academy of Pediatrics Steering Committee on Quality Improvement and Management. Classifying recommendations for clinical practice guidelines. Pediatrics. 2004;114(3):874-881. Available from: https://doi.org/10. 1542/peds.2004-1260.

5. Sadleir LG, Scheffer IE. Febrile seizures. BMJ. 2007;334(7588):307-311. Available from: https://dx.doi.org/ 10.1136/bmj.39087.691817.ae.

6. Febrile seizures: Clinical practice guideline for the longterm management of the child with simple febrile seizures. Pediatrics. 2008;121(6):1281-1287. Available from: https:// doi.org/10.1542/peds.2008-0939.

7. Daoud A, Batieha A, Abu-Ekteish F, Gharaibeh N, Ajlouni S, Hijazi S. Iron Status: A Possible Risk Factor for the First Febrile Seizure. Epilepsia. 2002;43(7):740-743. Available from: https://dx.doi.org/10.1046/j.1528-1157.2002.32501.x.

8. Hartfield DS, Tan J, Yager JY, Rosychuk RJ, Spady D, Haines $\mathrm{C}$, et al. The Association Between Iron Deficiency and Febrile Seizures in Childhood. Clin Pediatr. 2009;48(4):420-426. Available from: https://dx.doi.org/10. 1177/0009922809331800.

9. Berg AT, Shinnar S, Shapiro ED, Salomon ME, Crain EF, Hauser WA. Risk Factors for a First Febrile Seizure: A Matched Case-Control Study. Epilepsia. 1995;36(4):334-341. Available from: https://dx.doi.org/10.1111/j.1528-1157.1995.tb01006.x.

10. ;2015. 
Table 5: Comparison with different researchers

\begin{tabular}{|c|c|c|c|c|c|c|c|c|}
\hline Study & $\begin{array}{l}\text { Age } \\
(\mathrm{mts})\end{array}$ & $\begin{array}{l}\text { Hb } \\
(\mathrm{g}) \%\end{array}$ & $\begin{array}{l}\text { MCV } \\
\text { (fl) }\end{array}$ & $\begin{array}{l}\text { MCH } \\
\text { (pg) }\end{array}$ & $\begin{array}{l}\mathbf{P F} \\
(\mu \mathbf{g} / \mathbf{d l})\end{array}$ & $\begin{array}{ll}\mathbf{S .} & \mathbf{F e} \\
(\mu \mathrm{g} / \mathrm{d}) & \end{array}$ & $\begin{array}{l}\text { TIBC } \\
(\mu \mathrm{g} / \mathbf{d l})\end{array}$ & $\begin{array}{l}\text { STransf } \\
(\mathrm{mg} / \mathrm{dl})\end{array}$ \\
\hline Kobrinsky et al, ${ }^{[15]}$ & $6-36$ & $<11$ & $<72$ & $<24$ & $<20$ & - & - & - \\
\hline Pisacane et al, ${ }^{[16]}$ & $6-24$ & 10.5 & $<70$ & & $<5$ & - & - & - \\
\hline Daoud et al, [7] & $3-72$ & $<11$ & $<72$ & $<24$ & $<30$ & - & - & $-\mathrm{t}$ \\
\hline $\begin{array}{l}\text { Naveed-ur and Billoo et } \\
\text { al, }{ }^{[17]}\end{array}$ & $8-36$ & $<10$ & $<70$ & $<24$ & $<10$ & - & - & - \\
\hline Khalid N et al, ${ }^{[19]}$ & $13-18$ & $8.2-9.6$ & $55-63$ & $8-14$ & - & - & $438-575$ & - \\
\hline Present study & $6-60$ & $<11$ & $<70$ & $<27$ & $<12$ & $<60$ & $>450$ & $<250$ \\
\hline
\end{tabular}

11. International Institute for Population Sciences(IIPS) and ICF 2017. National Family Health Survey (NFHS-4);p. 2015-2031.

12. World Health Organization. Iron Deficiency Anemia. Assessment, Prevention and Control. A Guide for Program Managers. WHO/NHD/013. Geneva; 2001.

13. Beard J. Iron deficiency alters brain development and functioning. J Nutr. 2003;133(5):1468-72. Available from: https://doi.org/10.1093/jn/133.5.1468s.

14. Dube C, Richichi C, Bender RA. Temporal lobe epilepsy after experimental prolonged febrile seizures: prospective analysis; 2006. Available from: https://doi.org/10.1093/brain/awl018.

15. Kobrinsky NL, Yager JY, Cheang MS, Yatscoff RW, Tenenbein M. Does Iron Deficiency Raise the Seizure Threshold? J CHILD NEUROL. 1995;10(2):105-109. Available from: https://dx.doi.org/10.1177/088307389501000207.

16. Pisacane A, Sansone R, Impagliazzo N, Coppola A, Rolando P, D'Apuzzo A, et al. Iron deficiency anaemia and febrile convulsions: case-control study in children under 2 years. BMJ. 1996;313(7053):343-343. Available from: https://dx.doi.org/ 10.1136/bmj.313.7053.343.

17. Naveed-Ur-Rehman, Billoo AG. Association between iron deficiency anemia and febrile seizures. J Coll Physicians Surg
Pak. 2005;15(6):338-378.

18. Vaswani RK, Dharaskar PG, Kulkarni S, Ghosh K. Iron deficiency as a risk factor for first febrile seizure. Indian Pediatr. 2010;47(5):437-439. Available from: https://dx.doi. org/10.1007/s13312-010-0080-8.

19. Khalid N, Akrem M. The association between Iron Deficiency Anemia and First Febrile Convulsions. Duhok Med J. 2010;4(1):60-66.

Copyright: (C) the author(s), 2020. It is an open-access article distributed under the terms of the Creative Commons Attribution License (CC BY 4.0), which permits authors to retain ownership of the copyright for their content, and allow anyone to download, reuse, reprint, modify, distribute and/or copy the content as long as the original authors and source are cited.

How to cite this article: Rao VR, Kumar PA. Iron Deficiency Anemia as a Risk Factor for First Febrile Seizures a Case Control Study. Asian J. Clin. Pediatr. Neonatol. 2020;8(4):24-29.

DOI: dx.doi.org/10.47009/ajcpn.2020.8.4.6

Source of Support: Nil, Conflict of Interest: None declared. 